\title{
Study on blasting vibration reduction technology by digital detonator
}

\author{
E.A.CHI \& M.S.ZHAO \& Q.KANG* \\ Guizhou Xinlian Blasting Engineering Group Co.,Ltd., Guiyang, Guizhou, China
}

\begin{abstract}
Keywords: Hole-bottom air space charging; Air ration; Frequency band ; Blasting vibration; Stress Abstract. The delay precision of common detonator is not good, the actual time delay often have big difference with blasting design in real blasting engineering, and the blasting effect is difficult to control. While high precision digital detonators are instead of chemical drugs by original electronic control chip, so it has very high precision delay, and it is widely used in reducing blasting vibration and improving blasting effect. According to the contrast analysis of blasting vibration generated by digital electronic detonator and common detonator in actual situation, the total energy ratio of energy and D7 band ratio is regarded as index. Comparing results of the vibration reduction effect of digital detonator with common detonator proves that digital detonator in reducing blasting vibration effect is on superiority. It is worth to be promoted.
\end{abstract}

\section{Introduction}

The delay precision of common detonator is not good, the actual time delay often have big difference with blasting design in real blasting engineering, and the blasting effect is difficult to control. While high precision digital detonators are instead of chemical drugs by original electronic control chip, so it has very high precision delay, and it is widely used in reducing blasting vibration and improving blasting effect. Such as the precise time delay function of digital electronic detonator was used by Zhao Gen to conduct the field test of precise millisecond delay blasting, and the generated blasting seismic wave were monitored. Through comparative analysis of the test waveform, it can be found that: every section of the blasting seismic waves generally experienced three period, mean the main vibration cycle vibration, the first time vibration periods, and the second time vibration periods, the main vibration periods of time average of $5.8 \sim 8.8 \mathrm{~ms}$, averages $7.6 \mathrm{~ms}$. For the first time vibration periods of time average of $5.0 \sim 5.0 \mathrm{~ms}$, averages 6.9 $\mathrm{ms}$; The second vibration periods of time average of $2.8 \sim 7.8 \mathrm{~ms}$, averages $5.4 \mathrm{~ms}$. After analysis, based on the principle of not superposition of vibration amplitude, the adjacent period of delay time should be at least to ensure that the main seismic wave amplitude value is not superposition, namely, the interval time of adjacent segments should satisfy seismic dominant frequency peak with the first or the second peak of superposition of vibration. So it is recommended that the millisecond delay interval time between adjacent segments should be greater than the average of the main vibration period $8 \mathrm{~ms}$. The monitoring analysis of blasting vibration generated by using digital electronic detonator detonating technology under the condition of complex environments such as deep hole by Wen-xue Gao shows that: the digital electronic detonator can effectively control the harm effect of blasting vibration, improving the blasting effect; At the same time using presplit blasting can better control the strength of the blasting vibration; In addition, through optimizing millisecond delay interval time, low-frequency waves can be converted into uniform distribution of high-frequency seismic waves, so as to realize the effective control of blasting vibration damage.

This project combined with the earth flat field engineering of Zunyi city, and used the high precision digital detonator made in Guizhou, to make exploration and studying of controlling and improvement on blasting vibration effect. 


\section{Field Test}

\section{Test Equipment}

The JL series digital electronic detonator and its detonating system producted by GuiZhou JiuLian Industrial Explosive Materials Development Co.Ltd were used, which is shown in figure 1. This series production of digital electronic detonator with independent sets of circuit chips and applications software, can also set the electronic detonator detonating sequence and the delay time in the field. Its unique patented school method and time delay method, is more stable than using crystal vibration source of electronic detonator, and has the advantages of longer electronic detonator delay and more accurate than using common $\mathrm{RC}$ oscillation source of electronic detonator. The specific characteristics as follows: (1) the precision delay time, the error at same time is about $+1 \mathrm{~ms}$, and nominal rise time delay error when the change is very small; (2) without limitation of segment number, can according to the need of blasting engineering scene to set the initiation delay time, no segment, can be easily implemented in blasting engineering by hole precision millisecond delay controlled blasting, the scope of delay time from 1 to $60000 \mathrm{~ms}$ (interval $1 \mathrm{~ms}$ ); (3) good networking can be detected, the ID address of can network connected detonators and delay time can be scanned, getting address, delay time value and whether normal operation of every, ensuring reliable initiation; (4) has a very high security, only use the high security of special primer after password authentication to detonation, the ordinary power source such as battery, ac, dc $220 \mathrm{v}$ power frequency power supply can not initiate digital electronic detonator, so as the electrostatic, thunder and lightning, stray current, radio frequency will not mistaken detonation digital electronic detonator.

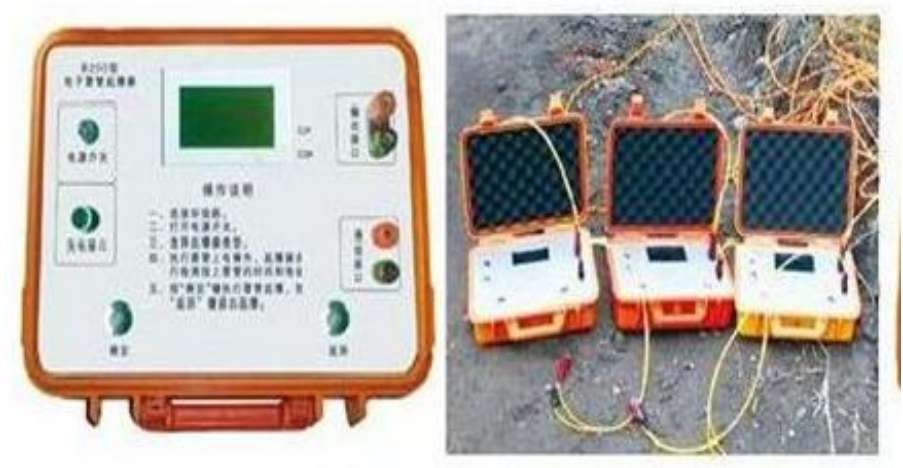

Fig.1 The JL series digital electronic detonator and its detonating system

\section{Date Monitoring}

The flat field blasting test data in zhunyi Sinpo Hongshuitai were chosen as sample, to make contrast analysis of blasting vibration intensity generated by the digital electronic detonator and common detonator. The excavation area of Hongshuitai flat engineering without overburden, for thick bedded rock dolomitic limestone (or block), fault development, regional block stability is good. The TC - 4850 type vibration measurer produced by chengdu zhongke measurement and control co., LTD was selected, its frequency response range: $5 \mathrm{hz}-500 \mathrm{hz}$, the accuracy of reading: $1 \%$, equipped with $\mathrm{X}, \mathrm{Y}, \mathrm{Z}$ three dimensional integrated speed sensor, 3 channel parallel sampling, the sampling frequency of $2000 \mathrm{~Hz}$. The site layout of vibration measurer is shown in figure 2 . 


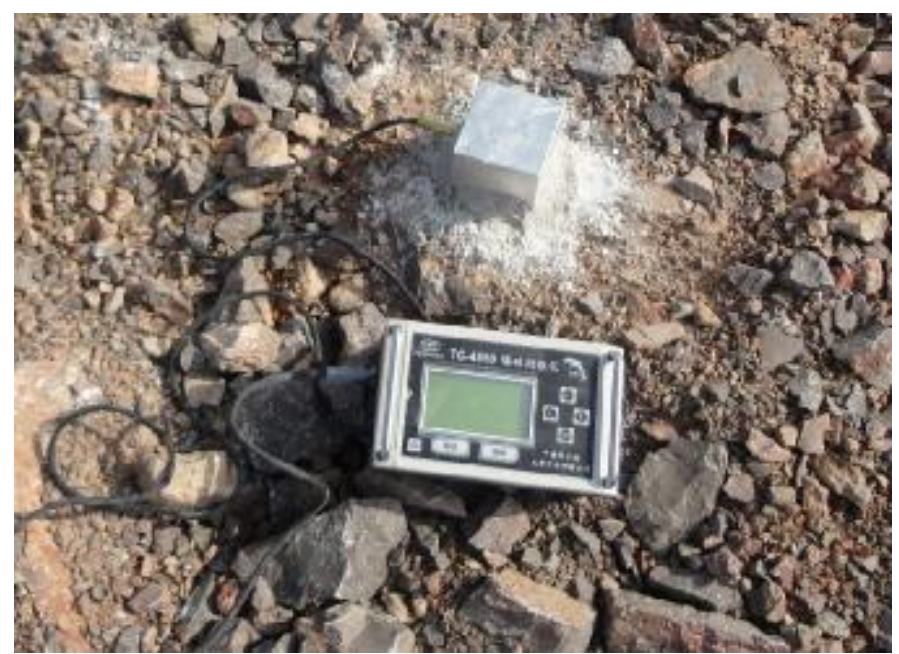

Fig.2 Arrangement of blasting vibration testing instrument

\section{Date Analysis}

To study of blasting vibration reduction effect by using of digital detonator, blasting particle vibration velocity peak value, frequency, continuous time, D7 frequency band energy ratio of digital detonator were compared with common detonator. The digital detonator millisecond intervals according to the analysis in section for protected buildings blasting center distance to determine. The common detonator uses 3 hole section detonator, 5 row section of hole by hole blasting. Two detonators have the same blasting scale and vibration monitoring blasting center distance. In order to compare vibration reduction effect of digital detonator with common detonator, the particle vibration peak velocity, frequency, duration and other statistics in figure 3 , figure 4, figure 5. From figure 3 , figure 4 , figure 5 , in addition to individual monitoring data due to site conditions or abnormalities caused by instrument installation, in contrast to the monitoring data for 15 times, the use of digital detonator blasting seismic wave particle vibration peak velocity of small, high frequency, short duration. These are good control of blasting vibration damage. Therefore, the total energy and D7 energy band of or digital detonator and common detonator is different. The control of blasting vibration effect is based on the viewpoint of energy. So it is necessary to do further analysis.

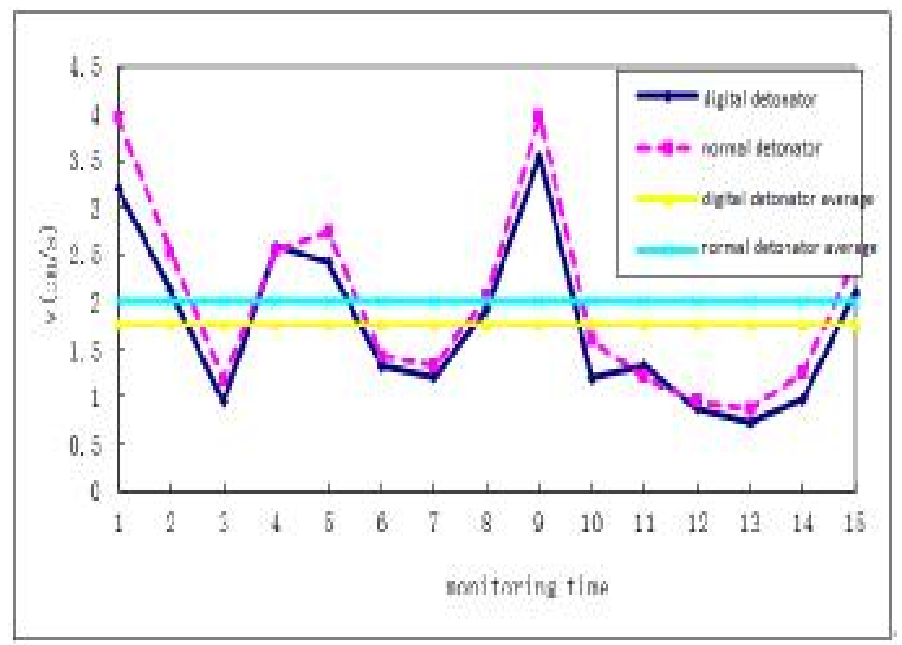

Fig. 3 the particle vibration velocity peak value of digital detonator and common detonator 


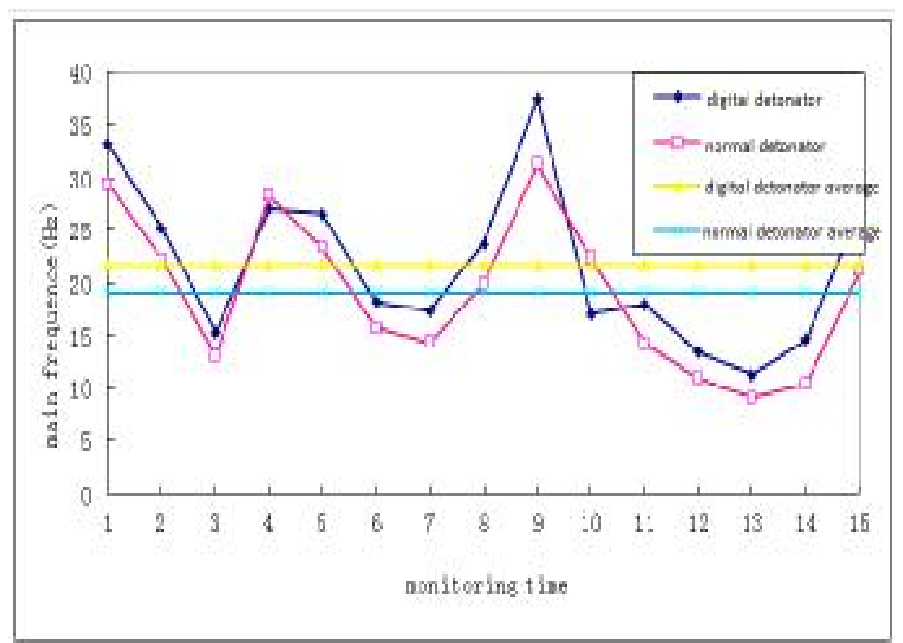

Fig.4 the main frequency of digital detonator and common detonator

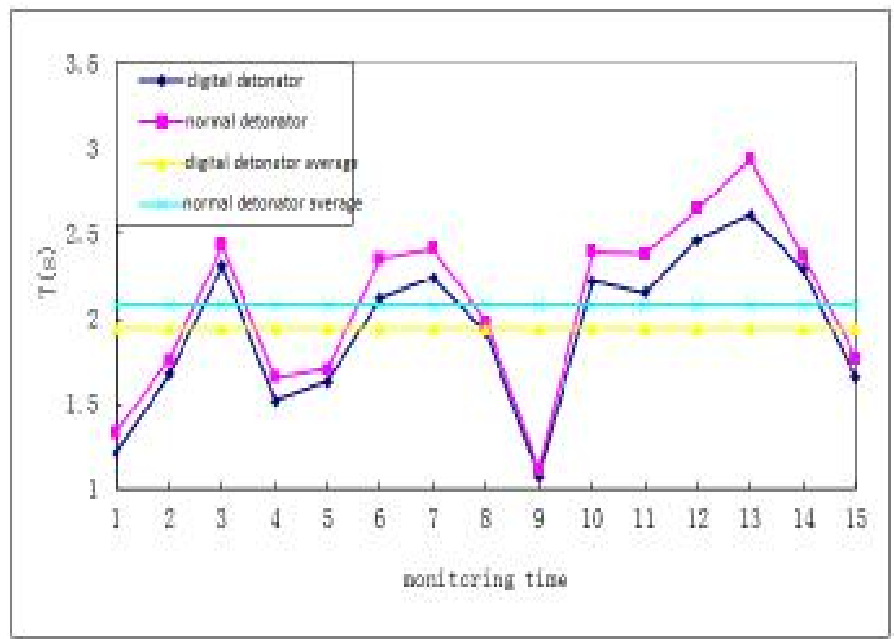

Fig. 5 the blasting seismic wave duration of digital detonator and common detonator

Using AOK time-frequency analysis to obtain three-dimensional spectral monitoring data and calculate the total energy of blasting seismic wave. Then the use of wavelet analysis of monitoring data of the monitoring data of D7 decomposition is used to obtain the frequency band energy. For ease of comparison, the total energy of digital detonator and common Detonator is analyzed. That is

$$
\mu=\frac{E_{D}}{E_{N}}
$$

In order to detonator D7 band energy burst compared with ordinary digital detonator guide. With digital detonator and common Nonel Detonator D7 band energy analysis. That is

$$
\theta=\frac{E_{D d 7}}{E_{N d 7}}
$$

The total energy statistics of he digital detonator and common Detonator is shown in figure 6, D7 frequency band energy ratio statistics is in figure 5. From figure 4, figure 7, in addition to individual monitoring data due to site conditions or abnormalities caused by instrument installation, in contrast to the monitoring data of 15 times, the total energy of blasting seismic waves of digital detonator are less than common detonator. Especially the D7 band minimum energy accounted for only $47 \%$ of the common detonator. So the use of digital detonator in reducing blasting vibration effect is on superiority. It is worth to be promoted. 


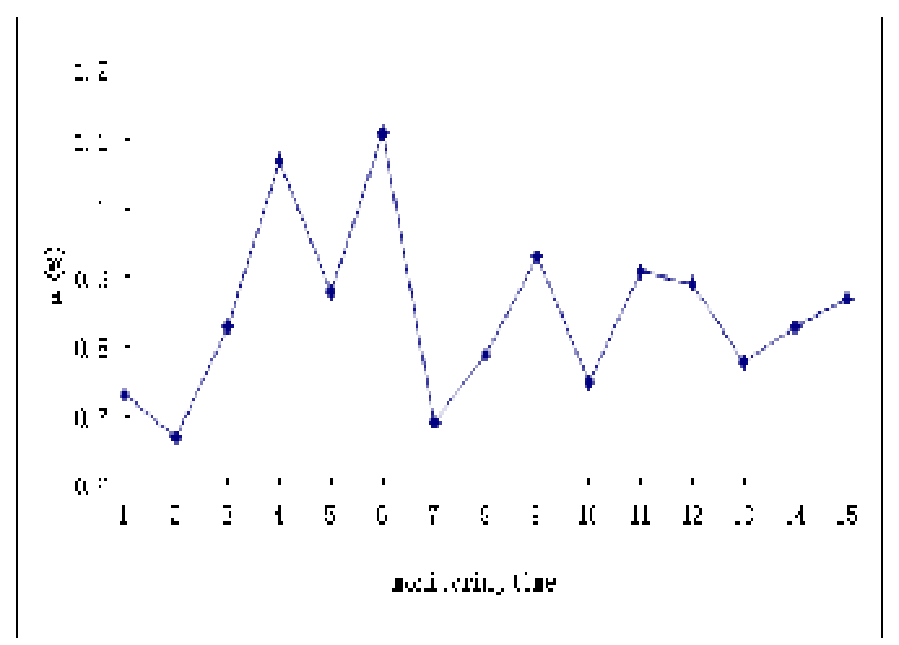

Fig. 6 blasting seismic wave total energy of digital detonator and common detonator

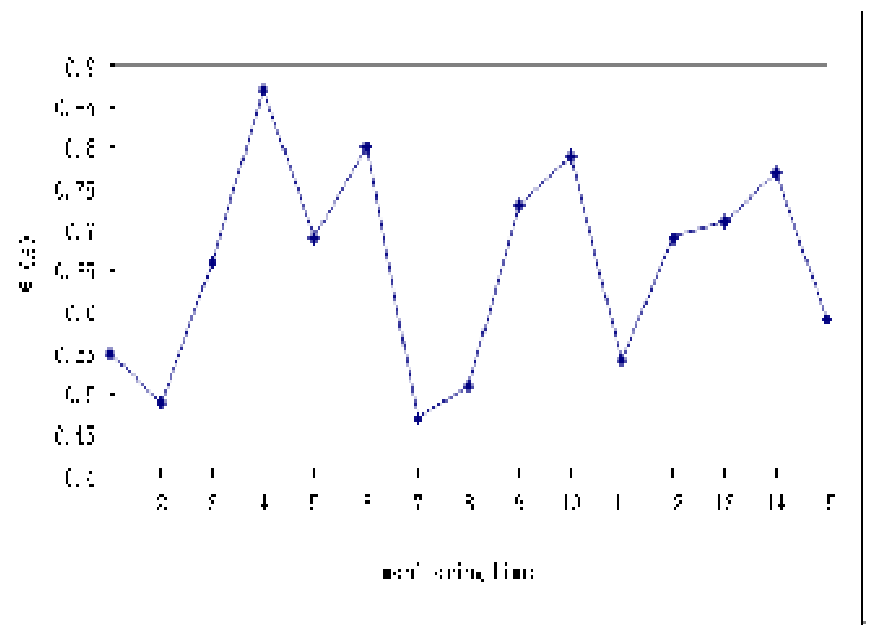

Fig.7 D7 band energy ratio of digital detonator and common detonator

According to the actual situation of the use of blasting equipment, the total energy ratio of energy and D7 band ratio is regarded as index. Comparing results of the vibration reduction effect of digital detonator with common detonator proves that digital detonator in reducing blasting vibration effect is on superiority. It is worth to be promoted.

\section{Summary}

The delay precision of common detonator is not good, the actual time delay often have big difference with blasting design in real blasting engineering, and the blasting effect is difficult to control. While high precision digital detonators are instead of chemical drugs by original electronic control chip, so it has very high precision delay, and it is widely used in reducing blasting vibration and improving blasting effect. The flat field blasting test data in zhunyi Sinpo Hongshuitai were chosen as sample, to make contrast analysis of blasting vibration intensity generated by the digital electronic detonator and common detonator. The analysis results showed that: According to the actual situation of the use of blasting equipment, the total energy ratio of energy and D7 band ratio is regarded as index. Comparing results of the vibration reduction effect of digital detonator with common detonator proves that digital detonator in reducing blasting vibration effect is on superiority. It is worth to be promoted.

\section{Acknowledgements}

This work was supported by the grants from the Guizhou Science and Technology Plan Project 
(No. SY2010365), Key Industrial Research Project Supported by Science Technology Department of Guizhou Province (No. (2013) 3013) and Guizhou Province Outstanding Young Scientific Talents Training Program Funded Projects (No. (2013) 30). These grants are gratefully acknowledged.

\section{References}

[1] Zhang Yiping. HHT analysis of blasting vibration and its application[D]. Changsha: Central South University, 2006.

[2] Wang Zhenyu, Liang $\mathrm{Xu}$, Chen Yinlu. Study of safety evolution method of blasting vibration based on input energy[J]. Chinese Journal of Rock Mechanics and Engineering, 2010, 29(12): 2492-2499.

[3] Li Hongtao. Study on effect of blast-induced seismic based on energy theory[D]. Wuhan: Wuhan University, 2007.

Zhao Mingsheng. Vibration effect of moderate-long hole bench blasting based on energy principle[D]. Wuhan: Wuhan University of technology, 2011.

[4] K.-G.HINZEN. Comparison of seismic and explosive energy in five smooth blasting test rounds[J]. International Journal of Rock Mechanics \& Mining Sciences, 1998, 35(7): 957-67.

[5] José A. Sanchidrián, Pablo Segarra, Lina M. López. Energy components in rock blasting[J]. International Journal of Rock Mechanics \& Mining Sciences, 2007, (44): 130-147.

[6] Fogelson DE, Atchinson TC, Duvall WI. Propagation of peak strainand strain energy for explosion-generated strain pulses in rock[C]/Proceedings of the third US symposium on rock mechanics. Golden: Colorado School of Mines, 1959: 271-284.

[7] Berg JW, Cook KL. Energies, magnitudes and amplitudes of seismicwaves from quarry blasts at Promontory and Lakeside[J]. Utah.Seismol Soc Bull, 1961, 51(3):389-400 